\section{Multidisciplinary \\ SCIENTIFIC JOURNAL OF MARITIME RESEARCH}

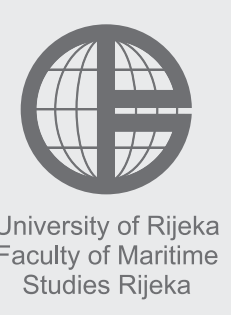

\section{Multidisciplinarni \\ znanstveni časopis POMORSTVO}

\title{
Maritime Common Good and Coastal Zone Management
}

\author{
Borna Debelić \\ University of Rijeka, Faculty of Maritime Studies, Studentska 2, 51000 Rijeka, Croatia, e-mail: debelic@pfri.hr
}

\author{
ARTICLE INFO \\ Original scientific paper \\ Received 6 May 2018 \\ Accepted 11 June 2018 \\ Key words: \\ Maritime common good \\ Commons \\ Classification of goods \\ Governance \\ Maritime domain \\ Coastal zone management
}

\section{Introduction}

Scarcity is a fundamental economic problem that manifests itself in the way that there are seemingly unlimited human needs and desires in the world of limited resources. Society does not have enough resources to meet every human need and desire. So, there is no society that can simultaneously realize all the plans and politics, and certain compromises are always necessary in the sense of adding one good to another (other) good(s).

Such an understanding of the problem of scarcity is well-perceived through the definition of economics provided by Robbins [26], originally published in 1932, which states that the economy is the science that studies human behaviour in terms of the relationship between goals and scarce resources that have an alternative purpose.

Because of the scarcity, different economic decisions have to be made in order to efficiently allocate the resources. In this context, it is possible to properly understand the economic law of scarcity in the sense that it marks a kind of principle according to which the majority of things that individuals want is available only in limited supplies (quantities). People have to make choices between different things because the resources necessary to meet their needs and wishes are limited. These decisions consist mainly of the abandonment (compromise) of some goods (resources) in order to enable other goods (resources) to themselves.

As economics can also be perceived as a study of human behaviour that is conditioned by the scarcity of the resources in order to achieve targeted goals, it is clear that scarcity is not an absolute [26], but a relative category. Scarcity does not signify a simple shortage (rare occurrence), but indicates constraints in relation to demand. Robbins [26] illustrates this problem on the example of good and spoiled eggs. In order to generalize this example, it is possible to say that the demanded (required) resource is scarce due to the demand for the same, while the unnecessary (not required) resource is not scarce in the economic sense of the word, but it is redundant. 
Similarly, the coastal zones are valuable for vast variety of possible ways of usage, and for different groups of individuals. In the same time they are scarce, so we need to find ways to satisfy exploitation demand as best as possible but in the same time to preserve the resource of such importance. The coastal zones and their integrity are of significant importance for societies that live in those areas, and whose life and economic activities are strongly pervaded by the sea. Their proper economic classification in the light of modern economic theories, as well as structural analysis, are of significant importance for studying and developing appropriate governance models able to comprehensively address variety of institutional arrangements and local specificities on the field. This is necessary to provide solid governance and institutional background that will enable achieving economic results while preserving sustainability of the resources, especially considering the well-known Hardin's [11] problem of the "tragedy of the commons" and possible solutions offered by modern scientific researches [20].

\section{International Formal Institutional Framework}

The importance of coastal zones is especially emphasized within the Mediterranean area. This is mainly a result of a style of life that has developed in that area strongly connected with the Mediterranean Sea that is almost completely enclosed by land, so tides are very limited as a result of the narrow connection with the Atlantic Ocean. Such characteristics have enabled the creation of strong links between people and coastal zones in their everyday life and work. In recent decades a strong growth in transport, tourism, fishing, industry and plenty of other economic activities connected with the sea have been marked by increasingly strong pressure on the coastal areas. As such, they require special attention in order to preserve their integral functionality.

The Barcelona Convention represents the legal basis on which the Mediterranean Action Plan - MAP is based, jointly representing a kind of international framework of the Mediterranean countries and the entire European Union aimed at protecting and enhancing the Mediterranean in the ecological and general development sense [19]. Sixteen Mediterranean countries, together with the European Union, adopted the Mediterranean Action Plan in 1975, which is the first ever regional seas program under the auspices of the United Nations Environment Program UNEP. Then, in 1976, the same parties involved adopted the Convention for the Protection of The Mediterranean Sea against Pollution - Barcelona Convention, which has so far been signed by a total of 21 countries of the Mediterranean and the European Union. The first version of the Barcelona Convention was signed in February 1976 and came into force two years later in February 1978. In the original version of the 1976 Barcelona Convention, respectively the 1975 Mediterranean Action Plan, the focus of interest was primarily the protection of the sea from pollution. Nevertheless, during the time the focus of the convention also extended to coastal areas through the multi-annual development of the idea of the protection of the marine environment and through the development of awareness that marine and land segments are indivisible, that is to say, integral in making a coherent unity.

Thus, in 1995, the original Mediterranean Action Plan was replaced by the new Action Plan for the Protection of the Marine Environment and the Sustainable Development of the Coastal Areas of the Mediterranean - MAP Phase II, adopted by the same signatories of the first version of the Action Plan from 1975. At the same time and in line with the same developmental orientations, the focus of the Barcelona Convention has also been extended to the integral planning and management of the coastal area. In accordance with these processes, in June 1995, the Convention was revised and renamed the Convention for the Protection of the Marine Environment and the Mediterranean [27].

The latest to date, the seventh protocol, called the Protocol on Integrated Coastal Zone Management in the Mediterranean - ICZM protocol [25], despite being the youngest of all the protocols and effective from March 2011, represents a serious institutional foundation for the expansion of the real impact of the Barcelona convention on to coastal zone management. In this context, the Barcelona convention and this protocol are important for the question of the classification, categorisation, allocation and governance of the coastal zone area.

The fundamental mission and purpose of the ICZM Protocol is to establish a common framework for the Integrated Coastal Zone Management of the Mediterranean in accordance with the Barcelona Convention and all its protocols and to take the necessary measures to strengthen regional cooperation. The area to which the ICZM Protocol applies comprises the coastal area of the Mediterranean Sea. It is defined by the border of the coastal area, in the seaward direction represented by the outer boundary of the territorial sea, while in the direction of the land represented by the boundary of the competent coastal unit as defined by the signatory states.

Between the six main objectives of the ICZM protocol [25], the first two are particularly important for our analysis. The first objective, aimed at enabling sustainable development of coastal areas through rational planning of activities and ensuring that the environment and landscape are taken into account in accordance with the economic, social and cultural development, is particularly emphasized by the use of two very important terms. The first is rationality in the sense of necessity for activities in the coastal area to be rationally planned in advance. The second is compatibility with economic development in the sense of the necessity of harmonizing economic, social and cultural development in the coastal areas. There is highlighting the need for the harmonization of general development with all other aspects of development of the coastal area. Nevertheless, the need to encourage the emergence and development of new and modern institutional forms with the function of strengthening the development of the coastal area as an integral system could still be added as 
one of the main parts of the objective. The second objective, aimed at preserving coastal areas for the benefit of present and future generations, highlights the immense importance of long-term preservation of the coastal area as a precious and specific resource for the benefit of coming generations to the same extent as it is useful for the present generations.

In addition to the aforementioned, worrying state of the marine environment and the totality of the coastal areas in the broadest sense, influenced by modern development trends, demonstrates the strong need for actions regarding more successful methods of governance and management. These methods and general allocation approaches are requiring more sophisticated analysis of coastal zones from the perspective of goods classification.

\section{Theoretical Background}

The theoretical concept of economic good is necessarily formal in the context of application of the classification of goods, as classification depends on the selected criteria. From the economics perspective, it is not possible to understand the quality of products and services outside of the domain of relationships with the people to whom those products and services are useful, that is, to which they are useful in terms of meeting the goals they are intended for. Whether a particular thing (product) or service really is economic good depends entirely on its relation to utility (value) [26].

According to the aforementioned, and simplifying arguments for the purpose of the imagination of reasoning, it is possible to conclude that neither wealth is a wealth because of its essential characteristics, but because it is seldom [26]. In a physical sense, it is not possible to determine the wealth, as it is for example possible with the determination of food in terms of their nutritive value. Richness is by itself necessarily a relative category [26], in which ordinal (and not cardinal) values have a dominant role. In one society (group) something can be abundant to the extent that it is free and can even be excessive in the ultimate sense. At the same time it may be economic good in the other society (group). Likewise, when it comes to manufacturing strengths in an economic sense, it is not thought to anything absolutely in the sense of physical computation, but is thought to be in the power of satisfying the needs with respect to a given demand. If demand is changed, then the production forces would have changed in that sense. What is here emphasised is a relativity of analytical understanding of goods in the economic sense, depending on the specific conditions of an environment to which a matter relates.

Perceiving the allocation mechanisms in the light of the economic reality, it is important to point out that allocative mechanisms are in a tight and inextricable connection with the characteristics and types of goods. The approach of the earlier economic theories, namely till the beginning of the second half of the $20^{\text {th }}$ century, was based on the duality of goods classification into private or public goods. Such an approach to the theoretical duality of the types of goods in earlier theories is correspondingly expressed with the dual- ity of the organizational - allocation approach in the form of a private enterprise - market vs. public authority. The market was seen as the optimal institution for intermediation in production and exchange, or allocation, of private goods. For non-private (public) goods, it was considered that public authorities needed to establish rules and fiscal mechanisms in order to force a selfish individual to contribute to the necessary public resources as well as refrain from activities solely aimed at satisfying their own selfish interests at the expense of the exploitation of a scarce resource [20]. It was considered that in the absence of a hierarchy in the form of public authority, and consequently without establishing rules to ensure compliance with public provisions, selfish citizens and civil servants would be unsuccessful in achieving an effective level of public goods such as peace and security at all levels of observation [31]. Furthermore, the allocative presence of a central government (public) authority has been theoretically rigorously recommended to reduce inadequacy in the structure of local municipal authorities, as well as to increase efficiency or limit the conflicts between government units and ultimately as an expression of homogeneity of public attitudes [3], [10], [9]. Samuelson [28] summed up and elaborated the classification of goods into two types. On the one hand, there are pure private goods that are, by their immanent properties, excludable and rivalrous, while on the other hand there are public goods that are nonexcludable and nonrivalrous in consumption. This basic classification was consistent with the previously expressed dichotomy in the form of an institutional economic aspect divided into private property - private goods exchanged on the market, and public property - public goods that are allocatively organized through the public authority system.

Such a theoretically dichotomous perspective has largely been able to explain the forms of interaction and outcomes related to market production and the exchange of strictly private goods [2], but it is not fully applicable to the explication of internal dynamics within private companies [32], [33], nor to the wide variety of institutional arrangements established in order to manage the allocation mechanisms and processes that do not fall into the category of private goods [20]. In earlier theories there was also a presumption that individuals are in principle understood as perfectly rational subjects, which was equally assumed in the theory of rational choice and the game theory modelling interactions between individuals and groups under full, partial or no collision of interests. For a fully rational individual it is assumed that he or she knows all possible strategies available in a given situation, the outcomes associated with the available strategies with known probabilities of other participants' behaviour in the given situation, and the order of each of the possible outcomes according to personal individual preferences measured through utility. The rational strategy of such an individual in each situation is the one leading to the maximisation of the expected benefits [20]. While theoretically utility was perceived as a way of combining different exterior values within a unique internal scale of individual values, in empirical practice it 
needs to be equated with an externalized unit of measure such as, for example, the expected profit. Such a model has undoubtedly generated theoretically useful and empirically valuable assumptions about the results of the transactions in a competitive market, but not in a variety of social dilemmas that occur in the allocation of goods that do not belong to the category of private goods [20]. In the classical economic theory, what was emphasized were the appropriateness of the allocation of private goods through classical market and public goods through public authorities and collective decisions making mechanisms in the public sector domain. Nevertheless, studying how individuals behave faced with different public problems led to theoretical needs of expanding the original Samuelson's dual classification of goods. First, Buchanan [5] introduced the third type of goods, which he called "club goods", marking them as excludable and nonrivalrous small-scale goods.

The introduction of the concept of polycentricism in the domain of economic governance and decision-making by Ostrom, Tiebout and Warren [24] marked a significant further progress in the efforts to understand the issues of production and providing of public services in metropolitan areas by diverse public and private agencies. The term polycentricity denotes more decision-making centres that are formally independent of each other. Whether they really are independent or rather make up a certain system of interrelated relations in the decision-making process, is per se the empirical question to be answered in each particular case [20], so it is impossible to generalize, but it is possible to detect systematic functioning with consistent and predictable action patterns and interactive activities [24].

With respect to the previously presented and reasoned triangulation of goods, theoretical set-ups have further advanced with Ostrom and Ostrom [23] providing additional contribution and introducing the fourth category of goods called commons or common pool resources, that are nonexcludable but rivalrous. So, they differ from the remaining three categories of goods in a way of existence of fundamental differences affecting, in allocative as well as governing terms, the encouragement of specific initiatives that individuals face in the exploitation of these goods. In recent years, scientific papers were mainly focused on refining and further aligning classification criteria [20], [21]:

- Replacing the term "rivalry in consumption" with "subtractability of use";

- Conceptualization of the subtractability of use and excludability in the way of being graded from low to high instead of being characterized as present or absent;

- Change the name of "club goods" to "toll goods" since many of these goods are supplied by smaller public and private associations with a fee (toll) to enjoy these goods. In accordance with the aforesaid, it is possible to determine two theoretical widely accepted criteria for the classification of goods:

- Ability to exclude potential users (beneficiaries) - excludability,

- Rivalry in consumption - subtractability.

The corresponding types of goods are shown in the Table 1.

Further theoretical developments [22], [14], [16], [17], [18], [21], [20] led to the creation of the Institutional Analysis and Development framework - IAD framework, as a specific research framework for institutional analysis and development which contains structural elements in the function of the implementation of economic research in the field of human interaction and the resulting outcomes through the spectrum of different situational and environmental settings, shown on the Figure 1.

Table 1 Classification of Goods

\begin{tabular}{|c|c|c|c|}
\hline \multirow[t]{2}{*}{ Excludability } & High & Toll goods & Private goods \\
\hline & \multirow[t]{2}{*}{ Low } & Public goods & Common goods \\
\hline & & Low & High \\
\hline
\end{tabular}

Source: Adapted from Ostrom $(2010,2005)$

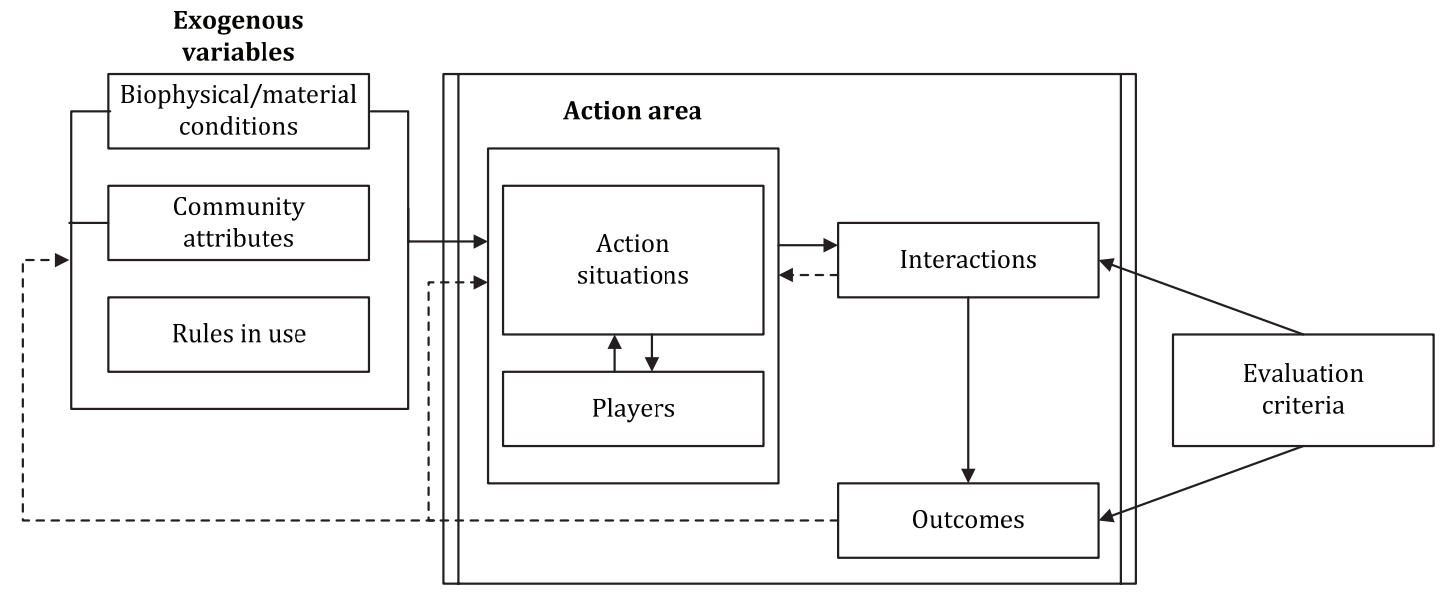

Figure 1 Institutional Analysis and Development framework 
Within the research framework, specific theories are set out that specify which parts of the research framework are considered for explaining different economic outcomes and behaviour and how they are interrelated. Theories of games, transaction costs theory, agency theory, public and common goods theory, public choice theory, rational choice theory and other are examples of specific theories that are compatible with the institutional analysis and development framework.

\section{Classification of Goods and Corresponding Criteria}

Dual criteria approach to the classification of goods and the effects of such classification provide more refined view of the goods for analytical purposes. However, such classification of goods based on two criteria (excludability and subtractability) to some extent is a limiting factor for studying deeper specifics of particular categories of complex goods. Mostly this division does not take into account one of the essential characteristics of resources - renewability, which greatly affects governing as well as allocation problems. Significant theoretical and applicative contributions by authors who specially addressed the problem of exhaustible resources [6] and renewable common pool resources [1] served as a basis for proposing improvements and upgrades of the existing knowledge about the types of goods and the classification criteria.
Based on the theoretical analysis and empirical research, considering the possibilities to complement theoretical knowledge and classification of goods, the classification of goods according to the three possible classification criteria is performed:

- Ability to exclude potential users,

- Subtractability of use,

- Renewability - possibility of a good to renew.

According to the stipulated criteria, goods can be classified into 8 main classes - types, as it is displayed in the three dimensional matrix (Figure 2).

There are three criteria for the classification of goods in the three coordinate sections, and on each axis the intensity of a particular criterion ranges from 0 (minimally expressed) to 1 (maximally expressed). This is a fine gradation consistent with contemporary scientific approach demonstrated by Ostrom [20] about the need to fine-tune the expression of certain classification criteria for a particular type (group) of goods. This classification of goods according to the three criteria covers eight classes of goods [7]:

- non-renewable public goods,

- non-renewable private goods,

- non-renewable common goods,

- non-renewable toll goods,

- renewable public goods,

- renewable private goods,

- renewable common goods,

- renewable toll goods.

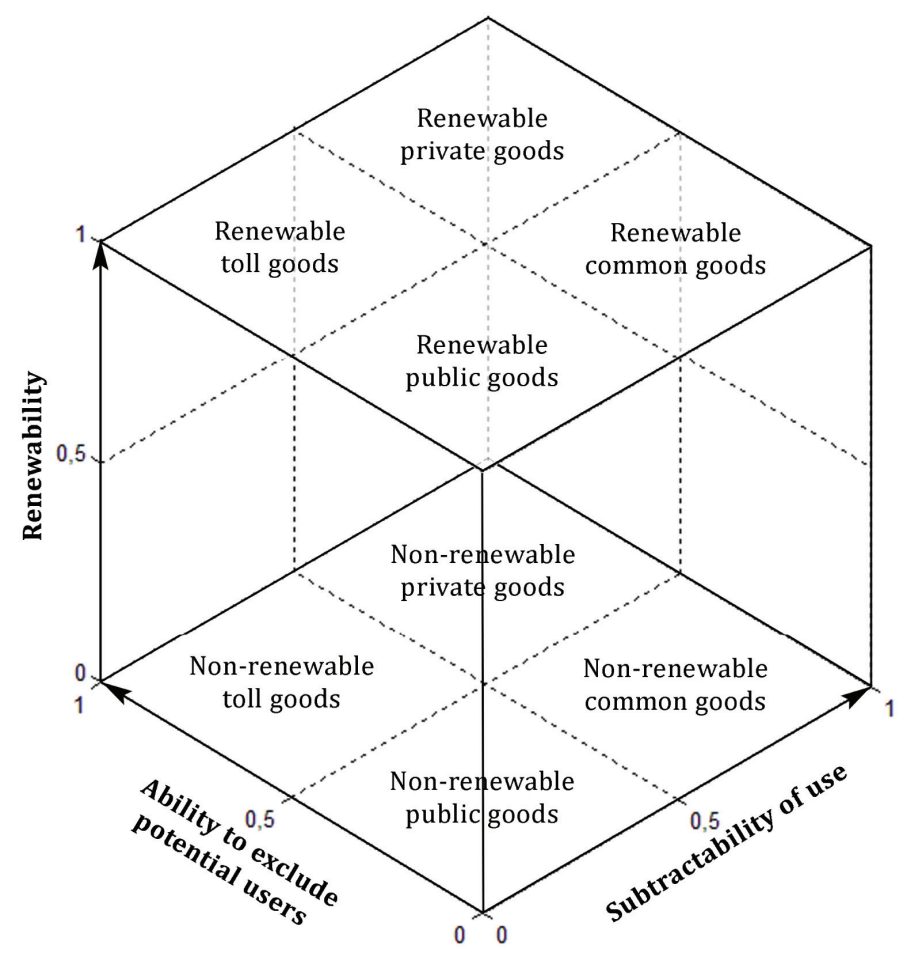

Figure 2 Classification of Goods According to the Three Criteria 
It is important to emphasize that, in addition to the degree of excludability and subtractability, the criteria of renewability of goods can also be graded from the complete lack of renewability of a particular good (on a coordinate axis marked with 0 ) through partial renewability to the maximal expression of the renewability of the good (at the coordinate axis indicated by 1). Consequently, the coordinate axis shows the intensity of the renewability ranged also from 0 to 1 . Similarly, it is also possible to disregard the grading along the criterion of renewability, and to assume that a good is renewable or non-renewable. This is complementary with numerous scientific researches that explore either renewable or non-renewable resources. This omission of fine grading along the criterion of renewability is illustrated in the scheme by depicting non-renewable goods on a further surface of the imaginary cubes (three-dimensional graph), and by depicting renewable goods on the upper surface of the cubes (three-dimensional graph). This allows that a good is classified as renewable or non-renewable.

But some goods may well be renewed faster or slower than some other goods. It cannot be neglected if a certain resource exposed to a certain level of exploitation can be renewed for a short or for a long time, and particularly important per se is the question about the level (intensity) of exploitation and its limits that are allowing the renewability. For this reasons, on the coordinate axis showing the criterion of renewability, there is a possibility of a finely graded renewability to take into account the small but important differences between goods resulting from their specific inherent characteristics.

Through elaborated precise grading of goods according to multiple criteria, there is a possibility of fine tuning the classification and analysis of certain types of goods and, consequently, analytical understanding of the immanent characteristics of each good is possible in the effort to improve the governance as well as all other economic aspects associated with this good. Provided extension of the goods classification criteria is particularly important for our analysis of the maritime common good, especially considering definition that we are offering and complexity of the good.

\section{Maritime Common Good}

Founded on the research framework and based on methodologically compatible modern economic theories, there is a need for the classification and analytical systematization of maritime common good that is presented in this paper, where IAD framework is utilised to provide the analytical understanding of the maritime good classification as well as the allocation problems arising. This is done in the light of ICZM protocol addressing the Mediterranean countries and their coastal zones as of special concern particularly considering the intensive interrelations between humans and coastal zones throughout long period of time.

The coastal zone is a very special form of resource due to its size, variety and complexity of structure as well as its importance for the maritime economy and generally, in the widest sense, for life on and around the sea. The resulting specificity greatly influences the diversity of local living and working conditions in both maritime and marine life. Considering the economic and social importance of coastal zones and integrated resources as well as the breadth of economic issues and features of coastal zone management, we can define the maritime common good as the comprehensiveness of life, work, resources and area in the sea and by the sea, taking into account the sea and coastal space, and all that is connected to them, as an inseparable integral unity to achieve desired effects, while preserving its sustainability to the benefit of the entire society, and with open access to everyone in accordance with the purpose of maritime good as well as institutional arrangements.

As an example, we can take Republic of Croatia through the perspective of spatial size and geographical coverage of the maritime domain that is substantial in size, particularly considering the relative size of the country. Instead of the term "maritime common good" that we are proposing here in order to adequately and comprehensively address its economic classification, significance, complexity and importance of integration, in this example we are deliberately using the term "maritime domain", as this is the term used so far in scientific literature. Several authors and sources addressed the size and coverage [12], [29], [30], [8] with slightly different data and measurements. Regardless of these differences, it is possible, with a high degree of certainty, to approximate that the surface of the inland waters and the territorial sea of the Republic of Croatia is around $31,100 \mathrm{~km}^{2}$, and the length of the sea coast is about $6,300 \mathrm{~km}$, out of which about 1,900 $\mathrm{km} \mathrm{(30 \% )} \mathrm{refers} \mathrm{to} \mathrm{the} \mathrm{mainland,} \mathrm{while} \mathrm{about} 4,400 \mathrm{~km}$ $(70 \%)$ to the shores of islands, islets, rocks and ridges.

This demonstrates the size, space and geographic scope in the physical sense. But the maritime resource importance must also include all the plant and animal worlds that immanently belong to the maritime common good and make with it an inseparable unity, economically and ecologically, as well as legally. Likewise, for a comprehensive and systematic understanding of the maritime common good, it is necessary to add all the mineral resources from the underground part, as well as to all the economic, social and cultural wealth that have for centuries been developed with an inseparable link to the sea and the maritime affairs and to the specific way of life around, on and from the sea.

From the Croatian legislative perspective, the maritime domain comprises of the seawater (covering internal sea waters and the territorial sea), their seabed and the underworld, and a part of the mainland that by its nature or purpose serves for the exploitation of the sea for maritime transport and fishing and other purposes related to the sea usage, and it is at least six meters wide from the mid high waters, from where it extends to the line up to the highest waves during stormy weather) [12], [4], [15]. Such a designation outlines mainly the spatial coverage emerging 
dominantly from the legislative foundations, but omits to properly address and emphasize its value as an economic good. Maritime domain, according to the Croatian law, is a good that is not capable of being the subject of ownership rights or other real rights, just as other parts of nature that by their properties cannot be owned by any physical or legal entities individually, but are in use of all [13].

Although the definitions of the maritime domain based on legal provisions are undoubtedly useful for recognizing legal issues, they do not take into account the breadth of economic significance and the integrity of the ecological aspect in its comprehensiveness with respect to the structural diversity. This is important in looking at the overall, rather than partial, perspective and complexity of the maritime common good. Therefore, there is a strong need for a comprehensive analysis with the apparatus of economic sciences and under the auspices of the economic perspective of observation in order to provide solid foundations for further improvements of the governing mechanisms and the general management of maritime affairs.

Bearing in mind the legislative determinations, and emphasising the economic and environmental integrity and the comprehensiveness of the coastal zones, as well as understanding those as a systematic integral resource with a strong need to ensure its long-term sustainability, it is possible to say that the maritime common good consists of two fundamental components:

- Living component,

- Non-living component.

The non-living component includes two segments:

- Spatial arrangement (distribution) and the size of the resource in terms of the territorial sea and inland wa- ters, the seabed and the underworld as well as the part of the land which is by its nature intended for common use or declared as such, as well as everything that the land is permanently connected with on the surface or below it;

- Service, cultural and social based values.

The living component includes two segments:

- Animal world of the sea and the coast;

- Botanical world of the sea and the coast.

From the definition and systematisation of the maritime common good, the complexity of the allocative and governing functions emerge, and for a precise and accurate addressing of them, it is necessary to analyse and demonstrate the characteristics of excludability and subtractability in use.

From the point of view of utilization, the maritime common good can be equally used by anybody under the condition that one respects its nature and purpose, so the common usage of the maritime good implies that everyone has the right to utilise the good according to its nature and purpose. Based on the aforesaid regarding the right of ownership, the fundamental characteristic of the maritime common good is that it belongs to everyone. In this sense, maritime common good is inalienable, and cannot be the object of acquisition of ownership or other real rights, and cannot be subject of trade.

There is a significant level of inability to control and limit the access to all of the components of the maritime common good, so there is a limited abbility to exclude potential beneficiaries of the maritime common good. This inability to exclude potential users is manifested in both the living and the non-living component of the maritime

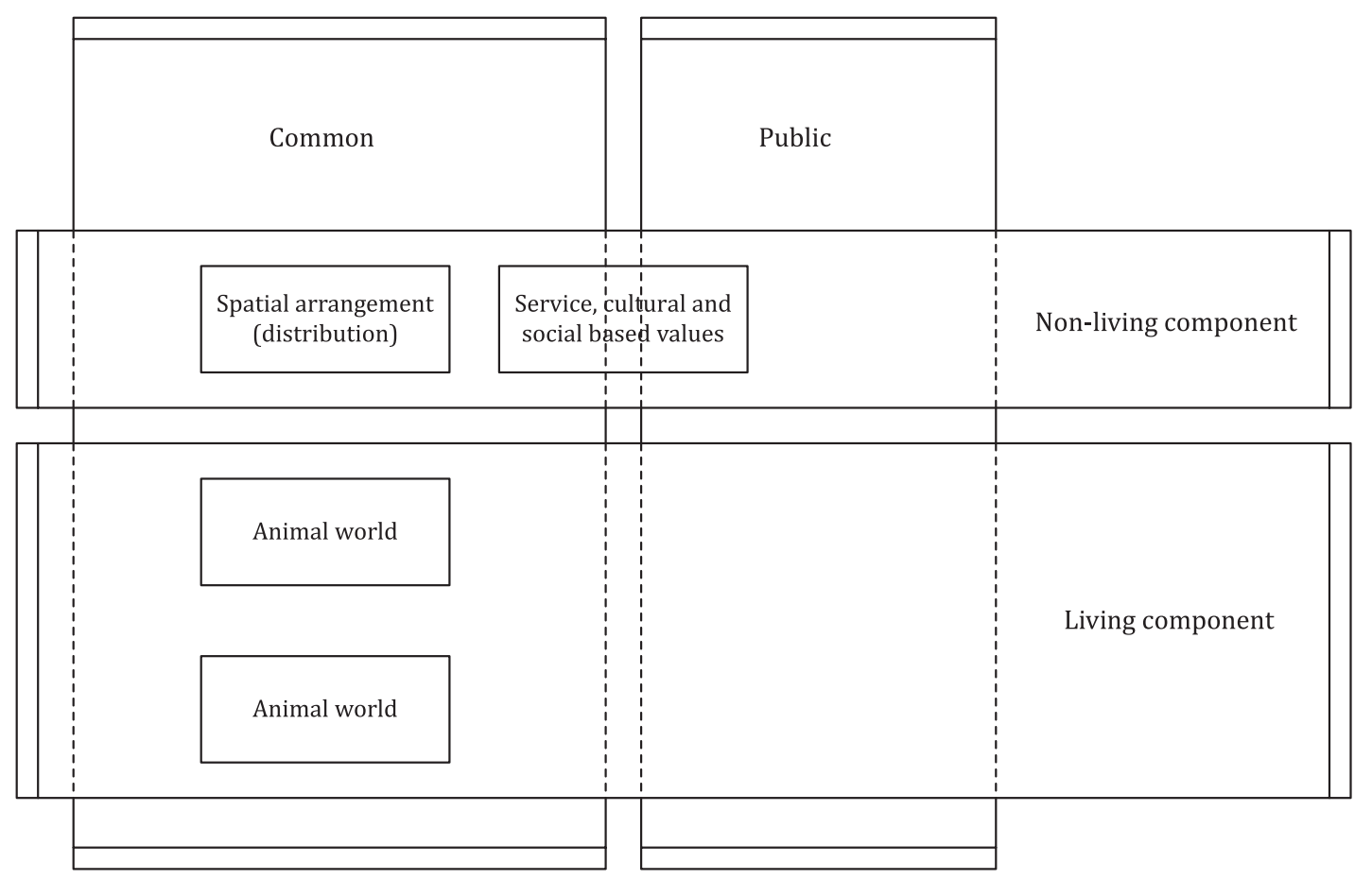

Figure 3 Components and Segments of the Maritime Common Good 
common good. Given the spatial and resource intensity of the maritime good, it is very difficult to exclude an individual from the usage irrespective of how much he or she contributes or not to the preservation of the good.

According to the above, it is possible to conclude that with the maritime common good there is present a significant inability to exclude potential beneficiaries. Nevertheless, it is important to mention that this excludability can be perceived as possible on some special parts of the coastal zones that can be taken out of the common usage by some specific decision (e.g. concession) and then it can be possible to partially exclude users on such a limited area. But, in order for a maritime common good to stay a real economic good capable of providing the breadth of its usable values, it is necessary that such a specific area remains in the minority because, otherwise, the integral functionality of the maritime common good would at least become doubtful, if not fully disabled.

Analysing the maritime good from the perspective of the criteria of subtractability in use, it is also necessary to consider this characteristic for all of its components and segments. Both the living and the non-living component present a significant level of subtractability in use in line with the considerations of modern theories. This subtractability is reflected with the existence of a rivalry among users. If someone occupies a portion of the maritime common good for the purpose of a particular activity/ exploitation, then it reduces the availability for all other users. Likewise, if certain mining resource is extracted from the sea bed and sea soil, then its availability is reduced for other potential users. This covers the issues of subtractability in the segment of the non-living component refer- ring to the spatial deployment and the size of the resource. This segment is dominant in the focus of the common users along with the living component that also strongly demonstrates a significant level of subtractability in use. One of the essential differences between the living and the nonliving component is the question of the third classification criterion introduced in this work - renewability. This problem of renewability can be the cause of certain confusion and imprecise observation of the two components of the maritime good, and therefore the question of renewal has been introduced in this work as a criterion for a more fine and precise classification in order to improve the theoretical and applicative aspects of the economic categories. Namely, the living component of the maritime good has characteristics of renewability as long as appropriation (exploitation) is within an acceptable level (intensity), and if the level of appropriation exceeded the level at which natural regeneration would be possible, then the renewability would be lost. However, it is very important to emphasize that the question about the level of appropriation that a resource can regenerate is not a simple matter and requires substantial amount of the specific knowledge of local conditions as well as field experience. On the other hand, the non-living component does not have renewability characteristics. This renewability gradation is illustrated in the matrix with an arrow (Figure 4).

However, within the non-living component, dominated by the segment of spatial deployment and the size of the resource, there is also the second segment which is seen as a complementarity of service (including traffic and transport), cultural and social based values, demonstrating low level of subtractability in use. Namely, this seg-

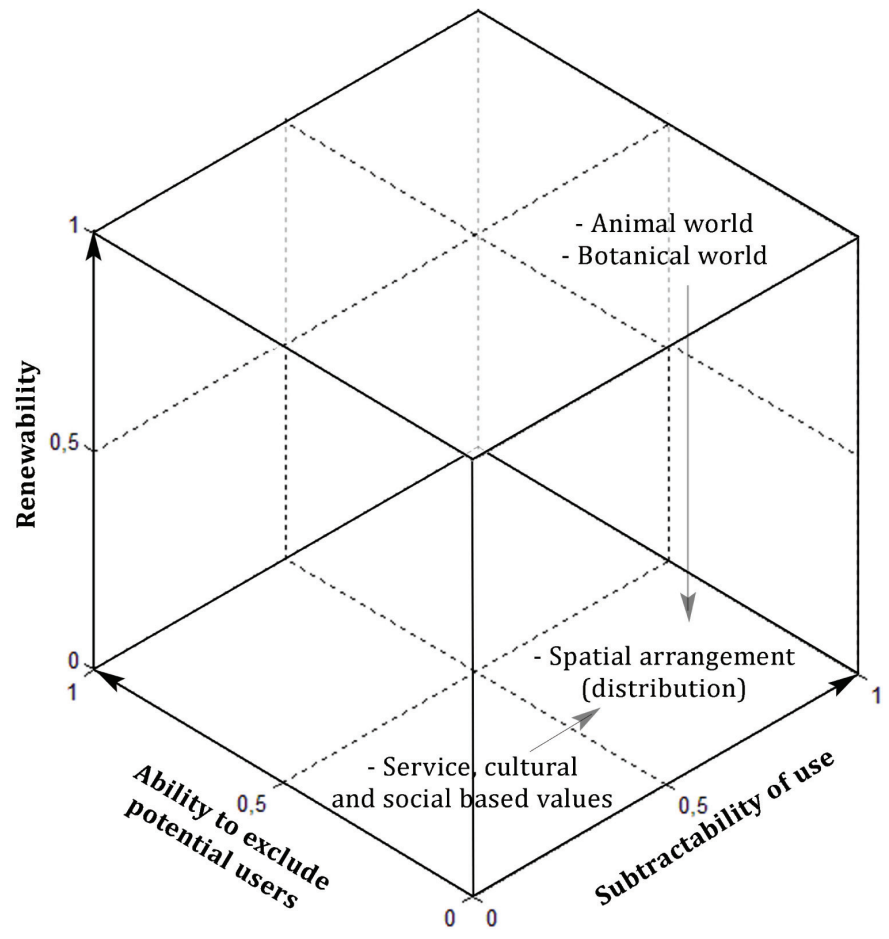

Figure 4 Segments of Maritime Common Good According to the Three Criteria 
ment illustrated by a possible example of valuable and protected amphorae sites, ancient cultural monuments and other cultural buildings built on the naval property, customs related to specific forms of exploitation of the sea and coastal areas such as corals and sponges, customs related to a specific way of life around, on and from the sea, etc., do not have a distinct characteristic in use. Nevertheless, the service aspect of the utility has a lesser degree of subtractability in use if the issues of congestion and bottlenecks are taken into account. This subtractability gradation is illustrated in the matrix with an arrow.

\section{Conclusion}

A low level of excludability as a general inability to exclude potential users (beneficiaries) as well as a high level of subtractability, as rivalry in consumption, are characterizing the maritime common good. In the same time the maritime common goods can be analytically subdivided into two main components, each of them having two segments. As such, the maritime good by its dominant characteristics can be primarily classified as a complex common good with limited renewability. It should be also noted that it also possesses some of the characteristics of the public good in certain aspects. This is the segment of service, cultural and social based values.

Common goods are strongly characterised by the technological aspects that are limiting exclusion of users, since there is a certain physical impossibility of access control, so the possibility of excluding potential beneficiaries is limited. It is possible to say that maritime common good also shares this characteristic as it is essentially a part of its existence in the sense of the category of common goods. There is a high level of inability to control access and exclude potential users. Maritime common good is significantly marked by its characteristics in which there are difficulties or immanent limitations in the implementation of control over the use of the good. That prevents the transformation of maritime common good into a private good. This technologically conditioned inability to exclude beneficiaries is, however, not the only and sufficient reason for the categorization of the maritime good as a common good. Namely, along with the technologically conditioned inability to exclude potential beneficiaries, there are three additional inabilities to exclude potential beneficiaries detected for the maritime common good:

- Functionally conditioned inability (if the good would lose its integrity and become fragmented and without open access the functional utility would disappear - no one could use it for services, transport, traffic etc.);

- Socio-cultural institutionally conditioned inability (the way of life around, on and from the sea strictly requiring the open access and integrity - non-fragmentation);

- Ecologically conditioned inability (fragmentation and exclusion of open access would disable ecological and environmental preservation).
The complexity and characteristics of the maritime common good impose a potential problem of an excessive and uncontrolled exploitation, usurpation and general devastation which is broadly, theoretically and empirically, recognized as a problem of governing the commons. We are emphasising the need to seek for the theoretically founded and empirically feasible solutions in order to overcome the "tragedy of the commons". In the light of modern research approaches discussed, we have the opportunity to look for the solutions based on the theoretical and empirical foundations of self-governance, inclusive deliberative governance, as well as participative management, addressing wide variety of collective decision-making problems that are strongly correlated with allocation problems with the commons. Those theoretical approaches can provide fruitful background for further advancements of maritime common good governing mechanisms based on stakeholders' inclusion into decision-making processes, thus strengthening the potential of the mechanisms itself and the information background necessary for a successful management of the complex commons as the maritime common good is.

\section{Acknowledgments}

This paper is based on the fourth and fifth chapter of my dissertation, resulting from the research started in 2009. I wish to thank Marija Kaštelan Mrak and Nenad Smokrović for being so helpful mentors.

\section{References}

[1] Ahn, T. K, Ostrom, E., Walker, J. M. (2010). A common-pool resource experiment with postgraduate subjects from 41 countries. Ecological Economics, 69 (12), pp. 2624-2633.

[2] Alchian, A. A. (1950). Uncertainty, Evolution, and Economic Theory. The Journal of Political Economy, 58 (3), pp. 211221.

[3] Anderson, W., Weidner, E. W. (1950). American City Government. New York: Henry Holt.

[4] Bolanča, D. et al. (2005). Pomorsko dobro. Zagreb: Inženjerski biro.

[5] Buchanan, J. M. (1965). An Economic Theory of Clubs. Economica, 32 (125), pp. 1-14.

[6] Dasgupta, P. S., Heal, G. M. (1979). Economic Theory and Exhaustible Resources. Cambridge: Cambridge University Press.

[7] Debelić, B. (2013). Racionalizacija mehanizma alokacije pomorskog dobra republike hrvatske (doktorska disertacija). Rijeka: Ekonomski fakultet Sveučilišta u Rijeci.

[8] Duplančić Leder, T., Ujević, T., Čala, M. (2004). Duljine obalne crte i površine otoka na hrvatskom dijelu Jadranskog mora određene sa topografskih karata mjerila 1:25000. Geoadria, 9 (1), pp. 5-32.

[9] Friesema, H. P. (1966). The Metropolis and the Maze of Local Government. Urban Affairs Review, 2 (2), pp. 68-90.

[10] Gulick, L. (1957). Metropolitan Organization. The ANNALS of the American Academy of Political and Social Science, 314 (1), pp. 57-65. 
[11] Hardin, G. (1968). The Tragedy of the Commons, Science, 162, pp. 1243-1248.

[12] Jelavić, A. (2012). Pravni položaj pomorskog dobra. Naše more, 59 (1-2), pp. 22-35.

[13] Jug, J. (2004). Pravni status općih dobara, in: Antonić, Lj. et al. Nekretnine u pravnom prometu. Zagreb: Inženjerski biro.

[14] Kiser, L. L., Ostrom, E. (1982). The Three Worlds of Action: A Metatheoretical Synthesis of Institutional Approaches, in: Ostrom, E. Strategies of Political Inquiry. Beverly Hills: Sage, pp. 179-222.

[15] Kundih, B. (2005). Hrvatsko pomorsko dobro u teoriji i praksi. Rijeka: Hrvatski hidrografski institut.

[16] McGinnis, M. D. (1999). Polycentricity and Local Public Economies: Readings from the Workshop in Political Theory and Policy Analysis, Ann Arbor: University of Michigan Press.

[17] McGinnis, M. D. (1999b). Polycentric Governance and Development: Readings from the Workshop in Political Theory and Policy Analysis, Ann Arbor: University of Michigan Press.

[18] McGinnis, M. D. (2000). Polycentric Games and Institutions: Readings from the Workshop in Political Theory and Policy Analysis, Ann Arbor: University of Michigan Press.

[19] Mediterranean Action Plan (2013). <http://www.unepmap. org > (17.02.2013)

[20] Ostrom, E. (2010). Beyond Markets and States: Polycentric Governance of Complex Economic Systems. American Economic Review, 100 (3), pp. 641-672.

[21] Ostrom, E. (2005). Understanding Institutional Diversity. Princeton: Princeton University Press.
[22] Ostrom, V. (1975). Language, Theory and Empirical Research in Policy Analysis, Policy Studies Journal, 3 (3), pp. 274-282.

[23] Ostrom, V., Ostrom, E. (1977). Public Goods and Public Choices, in: Savas, E. S. Alternatives for Delivering Public Services: Toward Improved Performance. Boulder: Westview Press, pp. 7-49.

[24] Ostrom, V., Tiebout, C. M., Warren, R. (1961). The Organization of Government in Metropolitan Areas: A Theoretical Inquiry, American Political Science Review, 55 (4), pp. 831-842.

[25] Protocol on Integrated Coastal Zone Management in the Mediterranean (Official Journal L 34/2009)

[26] Robbins, L. (1945). An Essay on the Nature and Significance of Economic Science, 2nd ed. revised and extended. London: Macmillan and Co.

[27] Regional Seas Programme, (2012). <http://www.unep.ch/ regionalseas/> (07.12.2012)

[28] Samuelson, P. A. (1954). The Pure Theory of Public Expenditure. The Review of Economics and Statistics, 36 (4), pp. 387-389.

[29] Statistički ljetopis Republike Hrvatske (2011). Zagreb: Državni zavod za statistiku Republike Hrvatske.

[30] Statistički ljetopis Republike Hrvatske (2012). Zagreb: Državni zavod za statistiku Republike Hrvatske.

[31] Woodrow, W. (2009). Congressional Government: A Study in American Politics, 4th ed. New Brunswick: Transaction Publishers.

[32] Williamson, O. E. (1975). Markets and Hierarchies: Analysis and Antitrust Implications. New York: Free Press.

[33] Williamson, O. E. (2005). The Economics of Governance. American Economic Review, 95 (2), pp. 1-18. 